\title{
Introduction to accompany the special issue on light-harvesting
}

\author{
Robert E. Blankenship · Harry A. Frank • \\ Robert A. Niederman
}

Published online: 16 May 2014

(C) Springer Science+Business Media Dordrecht 2014

This special issue of Photosynthesis Research on lightharvesting systems was inspired by work presented at a Satellite Workshop on Light-Harvesting Systems held at Washington University, St. Louis, MO from August 8-11, 2013, in conjunction with the 16th International Congress on Photosynthesis. The workshop offered sessions on optical coherence effects in photosynthesis, non-photochemical quenching and acclimation to light environments, evolution, adaptation and biodiversity of light-harvesting pigment-protein complexes, structure and organization of antenna complexes, spectroscopy and dynamics, and artificial antenna systems. The meeting attracted over 150 scientists from around the world including prominent biochemists, biophysicists, plant physiologists, chemical physicists and theoretical and computational physical chemists who came either to present their research findings or to hear the latest advances on the light-harvesting aspects of photosynthesis. A significant amount of time was set aside for discussion and poster sessions, as well as oral presentations by students and postdoctoral fellows

R. E. Blankenship ( $\square)$

Departments of Biology and Chemistry, Washington University in St. Louis, One Brookings Drive, Campus Box 1137, St. Louis, MO 63130, USA

e-mail: Blankenship@wustl.edu

\section{H. A. Frank}

Department of Chemistry, University of Connecticut, 55 North Eagleville Road, Storrs, CT 06269-3060, USA

e-mail: harry.frank@uconn.edu

\section{R. A. Niederman}

Department of Molecular Biology and Biochemistry, Rutgers

University, A317 Nelson Biological Laboratories, Busch

Campus, 604 Allison Road, Piscataway, NJ 08854-8082, USA

e-mail: rniederm@rci.rutgers.edu judged to have the best posters. Also, an interesting and productive joint session was held with the Workshop on Cyanobacterial Systems that was taking place concurrently at Washington University.

The editors wish to thank the authors of the papers presented in this special issue for their conscientiousness in submitting their manuscripts in a timely fashion. In addition, we thank the publisher, the editorial staff at Photosynthesis Research, and the Editor-in-Chief, David Knaff, for his encouragement and support. Support from a US Department of Energy Office of Basic Energy Sciences Conference grant is gratefully acknowledged. We also wish to express our gratitude to the support team of the Photosynthetic Antenna Research Center (PARC), an Energy Frontier Research Center funded by the US Department of Energy, Office of Science, Office of Basic Energy Sciences, especially Kaslina Love-Mosley, Erin Plut and Dan Allen for their valuable assistance in implementing the Workshop in St. Louis. Their efforts and those of the others named above were instrumental in helping us provide the readers of this issue of Photosynthesis Research with a collection of works that are interesting and important in the area of light-harvesting.

Sincerely,

Robert E. Blankenship Harry A. Frank

Robert A. Niederman 